\title{
Fisiologia pós-colheita de frutos da palmeira Mauritia vinifera Mart. (Arecaceae) $^{1}$
}

\author{
Paulo Santelli², Maria Elisa Ribeiro Calbo ${ }^{2}$ e Adonai Gimenez Calbo ${ }^{3,4}$
}

Recebido em 3/04/2008. Aceito em 9/10/2008

RESUMO - (Fisiologia pós-colheita de frutos da palmeira Mauritia vinifera Mart. (Arecaceae)). Alterações pós-colheita no amadurecimento dos frutos de Mauritia vinifera (buriti), colhidos com coloração marrom clara, foram estudadas acompanhando-se: massa, volumes gasosos intercelulares, concentração de $\mathrm{CO}_{2}$ e $\mathrm{O}_{2}$ na atmosfera interna, firmeza e as evoluções de $\mathrm{CO}_{2}$ e etileno, tanto a $25^{\circ} \mathrm{C}$ quanto sob baixa temperatura $\left(8{ }^{\circ} \mathrm{C}\right)$. Os frutos apresentaram injúria de resfriamento quando armazenados a $8{ }^{\circ} \mathrm{C}$ e não amadureceram ao serem retornados para $25^{\circ} \mathrm{C}$. Sob umidade elevada, baixa transpiração, a conservação do buriti triplicou em comparação com os frutos armazenados em ambiente menos úmido $(65$ a $85 \%)$. A casca resistente destes frutos perde a firmeza e o arranjo compacto das escamas e torna-se mais frágil e mais permeável a gases durante o amadurecimento ou quando armazenados sob temperatura que causa injuria de resfriamento. Os frutos de buriti contém apenas cerca de $1 \%$ volume gasoso intercelular, o que é indicativo de susceptibilidade à injúria de impacto, mediante descolamento de escamas. No amadurecimento a polpa torna-se macia, conforme leitura de penetrômetro, diminuindo a resistência ao transporte dos frutos, que passam a ser facilmente amassados. Estes frutos apresentaram comportamento climatérico típico e o pico de evolução de $\mathrm{CO}_{2}$ ocorreu dois dias após o pico do etileno. As curvas de concentração interna de $\mathrm{CO}_{2}$ e de $\mathrm{O}_{2}$ no buriti foram diferentes de outros frutos previamente estudados pelo fato de sofrerem uma grande redução da resistência difusiva da casca, causada pela formação das aberturas entre as escamas durante o amadurecimento.

Palavras-chave: amadurecimento, atmosfera interna, buriti, climatério, volumes gasosos intercelulares

ABSTRACT - (Postharvest physiology of Mauritia vinifera Mart. (Arecaceae) palm fruits). We studied postharvest ripening changes in Mauritia vinifera Mart. fruits, known as "buriti", harvested at a mature light-brown color stage, from palms on the Brazilian Central Plateau, as follows: weight loss, internal gaseous volume, internal $\mathrm{CO}_{2}$ and $\mathrm{O}_{2}$ concentration, firmness and $\mathrm{CO}_{2}$ and ethylene evolution, at room temperature $\left(25^{\circ} \mathrm{C}\right)$ and at low temperature $\left(8{ }^{\circ} \mathrm{C}\right)$. M. vinifera fruits suffered chilling injury when stored at $8{ }^{\circ} \mathrm{C}$ and the damaged fruits failed to ripen upon return to $25^{\circ} \mathrm{C}$ storage. Subjected to low water loss in high humidity chambers $M$. vinifera fruit-storage life tripled when compared to less humid storage environment ( 65 to $85 \%$ ), also at $25{ }^{\circ} \mathrm{C}$. The hard $M$. vinifera fruit peel became more gas permeable as it loses firmness and tight scale arrangement during ripening and also during storage at stressful chilled temperatures. Intercellular gaseous volume was low in $M$. vinifera fruits, a fact that may increase susceptibility to impact injury caused by a tendency of the hard peel scales to split or unglue. As it ripens the fruit pulp became soft, as recorded by a penetrometer, thus reducing transport resistance, the fruit becoming susceptible to even modest compression. M. vinifera had typical climacteric ripening behavior with the $\mathrm{CO}_{2}$ peak occurring two days after the ethylene peak. The internal $\mathrm{CO}_{2}$ and $\mathrm{O}_{2}$ curves were different from those of previously described fruits because there was a great reduction in peel diffusion resistance caused by the formation of openings between the hard peel scales during ripening.

Key words: "buriti", chilling injury, climacteric, internal atmosphere, ripening

\section{Introdução}

Exploradas comercialmente na produção de óleo, amido, palmito, cera e fibras, as espécies da família Arecaceae, plantas conhecidas como palmeiras, apresentam grande importância econômica. São também utilizadas como fonte de alimentos, bebidas e como matéria-prima para construção de barcos, pontes e casas. As plantas são utilizadas na ornamentação de praças, jardins e ambientes internos há vários séculos. As palmeiras são de ocorrência predominantemente tropical (Henderson et al. 1995), têm a capacidade de se estabelecer em diversos tipos de habitat, como mata de terra firme, matas periodicamente inundadas, cerrado, e em ambientes degradados. No Brasil encontram-se extensamente distribuídas (Lorenzi et al. 2004).

A realização de estudos fisiológicos é fundamental para o conhecimento da ecofisiologia dessa família, e pode, ainda, contribuir para a preservação e propagação de suas espécies. Foi selecionada uma espécie muito comum no Distrito Federal (DF) Mauritia vinifera Mart. para estudos fisiológicos de seus frutos.
Mauritia vinifera Mart. é popularmente conhecida como buriti. É distribuída por toda a América do Sul, ocorrendo no Brasil nos estados do Amazonas, Pará, Maranhão, Piauí, Bahia, Ceará, Tocantins, Mato Grosso, Goiás, São Paulo e Distrito Federal, sendo freqüente nas baixadas úmidas de áreas de Cerrado do Brasil Central (Lorenzi et al. 2004). O buriti é a palmeira mais abundante no território brasileiro e ocorre comumente em agrupamentos quase homogêneos chamados buritizais (Lorenzi et al. 2004). É uma palmeira de pleno sol, adaptada a solos permanentemente inundados, de tronco simples, com flores dióicas e folhas perenes em forma de leque. $O$ fruto mede cerca de $4,0 \mathrm{~cm}$ de diâmetro e é em forma de uma drupa levemente ovalada, com a presença de uma única semente ovóide de consistência dura e amêndoa comestível. Possui polpa amarela, carnosa e comestível e é recoberto por escamas extremamente duras, de coloração marrom-avermelhado na maturidade (Correa 1931; Henderson et al. 1995).

Para frutos nativos do cerrado, existem poucos trabalhos em que se tenha avaliado a respiração e a evolução de etileno. Dentre estes, podem ser citados os estudo da cagaita

\footnotetext{
Parte da Dissertação de Mestrado do primeiro Autor

2 Universidade de Brasília, Departamento de Botânica, Laboratório de Fisiologia Vegetal, Brasília, DF, Brasil

3 EMBRAPA Instrumentação Agropecuária, São Carlos, SP, Brasil

4 Autor para correspondência: adonai@cnpdia.embrapa.br
} 
(Eugenia dysenterica DC.) (Calbo et al. 1990) e da gueroba (Syagrus oleracea (Mart.)Becc.) (Santelli et al. 2006). Para o buriti Souza et al. (1984) estudou alguns aspectos da maturação do fruto como: perda de peso, alterações de cor da casca e firmeza ao tato em frutos na temperatura ambiente e climatizados a uma temperatura de $18{ }^{\circ} \mathrm{C}$ sob $85 \%$ de umidade relativa. Amarante $\&$ Megguer (2008) avaliaram a qualidade pós-colheita de frutos de butiá (Butia eriospatha (Mart. ex Drude) Becc.) em função do estádio de maturação na colheita e do manejo da temperatura. Faltam, no entanto, estudos sobre a respiração, a evolução de etileno e o comportamento pós-colheita dos frutos do buriti em ambientes de armazenamento.

Este trabalho foi desenvolvido para ampliar o conhecimento da fisiologia e do comportamento pós-colheita dos frutos de buriti. Para este fim, foi estudada a evolução de $\mathrm{CO}_{2}$ e etileno em duas temperaturas; foi acompanhada a composição da atmosfera interna de seus frutos; foram quantificados os volumes gasosos intercelulares e foi acompanhada a firmeza dos frutos durante o amadurecimento.

\section{Material e métodos}

Os frutos da Mauritia vinifera Mart. (buriti) foram colhidos maduros, de coloração marrom clara, quando apresentam o desenvolvimento máximo. Coletados de populações nativas desta palmeira, nas coordenadas $15^{\circ} 51,463^{\prime} \mathrm{S}-47^{\circ} 52,555^{\prime} \mathrm{W}$, região da bacia do Paranoá próxima a SHIS QI 17, Brasília, DF, os frutos foram transportados, seja para o laboratório de Fisiologia Vegetal do Departamento de Botânica da UnB, seja para o Laboratório de Pós-Colheita da Embrapa Hortaliças. Houve cuidado para não expô-los à elevada temperatura e luz solar direta durante o trajeto, bem como à ventilação excessiva. Os frutos foram selecionados quanto à homogeneidade de cor e tamanho.

Experimento - Para medidas de evolução de etileno e $\mathrm{CO}_{2}$, os tratamentos avaliados foram $8{ }^{\circ} \mathrm{C} \pm 3{ }^{\circ} \mathrm{C}$ e $25{ }^{\circ} \mathrm{C} \pm 3{ }^{\circ} \mathrm{C}$ de temperatura para frutos armazenados em conjunto; o tratamento a temperatura ambiente $\left(25{ }^{\circ} \mathrm{C}\right)$ foi desdobrado em dois, um mantendo-se os frascos plenamente abertos (baixa umidade relativa) após as medições e outro os mantendo com uma reduzida passagem de ar (alta umidade relativa) através de dois orifícios de cerca de $1 \mathrm{~cm}$ de diâmetro, ou seja, os frascos encontravam-se fechados mas não vedados. Foram feitas seis repetições por tratamento e cada repetição continha seis frutos. Foi feito também um estudo com frutos individuais, com seis repetições. Este último tratamento com frutos individuais foi feito para verificar a relevância da ocorrência de etileno de frutos amadurecidos precocemente cuja evolução de etileno pode antecipar o amadurecimento dos demais frutos, no caso dos frutos serem climatéricos.

Avaliações - Os frutos foram pesados diariamente para acompanhar a perda de massa em cada uma das repetições. A evolução de $\mathrm{CO}_{2}$ e etileno foi medida em um sistema fechado, no qual os frutos em conjunto foram colocados em frascos de $2420 \mathrm{ml}$ e os frutos individuais em frascos de $602 \mathrm{ml}$. Amostras de $1 \mathrm{ml}$ foram extraídas com seringa hipodérmica, e injetadas em cromatógrafo a gás Finnigan modelo 9001, equipado com uma coluna "poropak N" e uma coluna de exclusão molecular. Foi usado hidrogênio a um fluxo de $30 \mathrm{ml} / \mathrm{min}$ como gás de arraste para as medições das concentrações de $\mathrm{CO}_{2}$ e etileno. Para acompanhar a evolução da concentração de $\mathrm{O}_{2}$ e $\mathrm{CO}_{2}$ na atmosfera interna dos frutos armazenados a $25^{\circ} \mathrm{C}$ foi utilizado o método da câmara externa de Devaux para extração da amostra seguido de análise no instrumento FACILI (Santelli et al. 2006). A seguir calculou-se ou resistência difusiva ( $r$ ) ou fator de conversão como a razão entre a concentração de $\mathrm{CO}_{2}$ da atmosfera interna (ci) contida nos espaços intercelulares em ml L-1, e a taxa de evolução de $\mathrm{CO}_{2}(\mathrm{R}) \mathrm{em} \mathrm{ml} \mathrm{kg}^{-1} \mathrm{~h}^{-1}$ $(\mathrm{r}=\mathrm{ci} / \mathrm{R})$ dos frutos. A porosidade ou porcentagem de volumes gasosos intercelulares foi calculada pelo método de Jensen et al. (1969) com modificações (Santelli et al. 2006).

Para as medidas de firmeza com o penetrômetro a gás (Calbo e Moretti 2005) os frutos de buriti foram acompanhados durante 15 dias em frascos abertos armazenados a $25{ }^{\circ} \mathrm{C} \pm 3{ }^{\circ} \mathrm{C}$ sob umidade relativa de $75 \% \pm 5 \%$. A cada dia foram escolhidos ao acaso 5 destes frutos e foram feitas duas medidas em kgf por fruto, utilizando-se ponteira cilíndrica com diâmetro de $3 \mathrm{~mm}$. Após a medição os frutos perfurados na medição eram descartados. Para esta leitura a casca foi removida e o penetrômetro foi pressionado contra o fruto até que este fosse perfurado.

Análise estatística - Com o software SANEST (Zonta \& Machado 1995) aplicou-se análise de variância pelo teste F e em seguida as médias foram comparadas pelo teste de Tukey a $5 \%$ de probabilidade.

\section{Resultados e discussão}

Respiração e evolução de etileno - No tratamento com frutos individuais armazenados em frascos destampados a $25^{\circ} \mathrm{C}$ o comportamento climatérico de evolução de etileno foi evidente e houve um pico máximo de evolução no $7^{\circ}$ dia com valor de $17 \mu \mathrm{L} \cdot \mathrm{kg}^{-1} \cdot \mathrm{h}^{-1}$ (Fig. 1). No tratamento, no qual os frutos em conjunto foram armazenados destampados a $25^{\circ} \mathrm{C}$ o comportamento climatérico se repetiu, porém com amadurecimento acelerado em um dia e evolução de etileno aumentada para $31 \mu \mathrm{L} \cdot \mathrm{kg}^{-1} \cdot \mathrm{h}^{-1}$. Neste caso, os efeitos observados possivelmente ocorreram porque algum(uns) do(s) fruto(s) em conjunto em estágio mais avançado de amadurecimento tenha(m) liberado etileno e assim tenha(m) causado a antecipação do amadurecimento e aumento na taxa de evolução de etileno. Nos frutos armazenados a $8{ }^{\circ} \mathrm{C}$ ocorreu o pico de etileno, e a taxa de foi estável e mais reduzida(Fig. 1), de maneira similar ao que foi verificado por Biale et.al (1954) para abacate (Persea americana Mill.) e cherimóia (Annona cherimola Mill.) armazenados a $5^{\circ} \mathrm{C}$.

Sob passagem de ar restrita dentro de frascos com dois pequenos orifícios de $1 \mathrm{~cm}^{2}$, a $25^{\circ} \mathrm{C}$, os frutos mantiveram os níveis pré-climatéricos de evolução de etileno por muito mais tempo e um pico de evolução do etileno (Fig. 1) menor, $7 \mu \mathrm{L} \cdot \mathrm{kg}^{-1} \cdot \mathrm{h}^{-1}$, ocorreu muito mais tarde, ao $25^{\circ}$ dia.

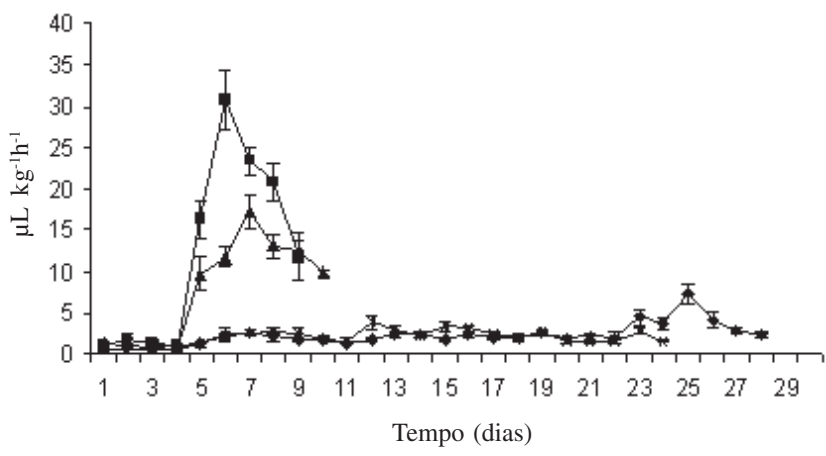

Figura 1. Evolução de etileno $\left(\mu \mathrm{L} \cdot \mathrm{kg}^{-1} \cdot \mathrm{h}^{-1}\right)$ em frutos de buriti (Mauritia vinifera Mart.) armazenados: em conjunto de cinco frutos a $25^{\circ} \mathrm{C}$ em frascos mantidos abertos no ambiente(-(口), a $25^{\circ} \mathrm{C}$ em frascos com frutos individuais mantidos abertos no ambiente $(\boldsymbol{\Lambda})$, em conjunto de cinco frutos a $25^{\circ} \mathrm{C}$ em frascos fechados com pouca passagem de $\operatorname{ar}(\bullet)$ e em conjunto de cinco frutos a $8{ }^{\circ} \mathrm{C}$ em frascos mantidos abertos $(\mathbf{x})$. As barras de intervalo representam o erro padrão da média. 
Consubstanciando um atraso de amadurecimento por este tratamento que apresenta potencial de utilidade prática para aumentar substancialmente a vida útil de pós-colheita dos frutos de buriti.

De uma maneira geral as amplitudes na evolução climatérica de etileno do buriti a $25^{\circ} \mathrm{C}$ (Fig. 1) são compatíveis com as variações entre níveis pré-climatéricos de $0,02 \mu \mathrm{L} . \mathrm{kg}^{-1} \cdot \mathrm{h}^{-1}$ e o nível de $130 \mu \mathrm{L} \cdot \mathrm{kg}^{-1} \cdot \mathrm{h}^{-1}$ no pico de evolução de etileno do abacate observado por Biale et al. (1954) e das variações de 0,02 a $100 \mathrm{~mL} \cdot \mathrm{kg}^{-1} \cdot \mathrm{h}^{-1}$ observados de maneira semelhante em frutos de maçã (Malus sp.) por Burg \& Thimann (1960).

Quanto ao padrão climatérico de evolução de $\mathrm{CO}_{2}$, observou-se que nos frutos armazenados em conjunto em frascos abertos a $25^{\circ} \mathrm{C}$ o pico na taxa de evolução de $\mathrm{CO}_{2}$ ocorreu no $8^{\circ}$ dia de armazenamento (Fig. 2), o que representa um atraso de dois dias em comparação com o pico do etileno (Fig. 1). Adicionalmente, para estes frutos a taxa de evolução de $\mathrm{CO}_{2}$ no pico, $138 \mathrm{~mL} \cdot \mathrm{kg}^{-1} \cdot \mathrm{h}^{-1}$ de $\mathrm{CO}_{2}$, foi maior que nos frutos armazenados individualmente, $77 \mathrm{~mL} \mathrm{~kg}{ }^{-1} \cdot \mathrm{h}^{-1} \mathrm{de} \mathrm{CO}_{2}$ (Fig. 2). Estes resultados são compatíveis com o atraso e a redução na evolução de etileno observada para frutos individuais na Fig. 1. Saliente-se, entretanto, que não houve atraso diferencial entre os picos de evolução de $\mathrm{CO}_{2}$ entre tratamentos de frutos individuais versus frutos armazenados em conjunto. Diferentemente do comportamento nos frutos em frascos abertos, no tratamento com restrita passagem de ar a $25^{\circ} \mathrm{C}$ houve um pequeno pico de $\mathrm{CO}_{2}$, de $61 \mathrm{~mL} \cdot \mathrm{kg}^{-1} \cdot \mathrm{h}^{-1}$ também ao $8^{\circ}$ dia e outro aumento na evolução a partir do $18^{\circ}$ dia de armazenamento com valores próximos a $40 \mathrm{~mL} \cdot \mathrm{kg}^{-1} \cdot \mathrm{h}^{-1} \mathrm{de} \mathrm{CO}_{2}$ (Fig. 2). Para os frutos armazenados a $8{ }^{\circ} \mathrm{C}$ a evolução de $\mathrm{CO}_{2}$ foi muito menor, tendo esta oscilado entre 6,5 e $17 \mathrm{~mL} \cdot \mathrm{kg}^{-1} \cdot \mathrm{h}^{-1}$. Comparativamente, algumas outras espécies de frutos climatéricos que apresentam picos de evolução de $\mathrm{CO}_{2}$ da mesma ordem de grandeza obtidas neste estudo são a feijoa (Acca sellowiana (O.Berg.) Burret) com $146 \mathrm{~mL} \cdot \mathrm{kg}^{-1} \cdot \mathrm{h}^{-1}$ e a banana (Musa sp.) com $160 \mathrm{~mL} \cdot \mathrm{kg}^{-1} \cdot \mathrm{h}^{-1}$ (Biale et al. 1954).

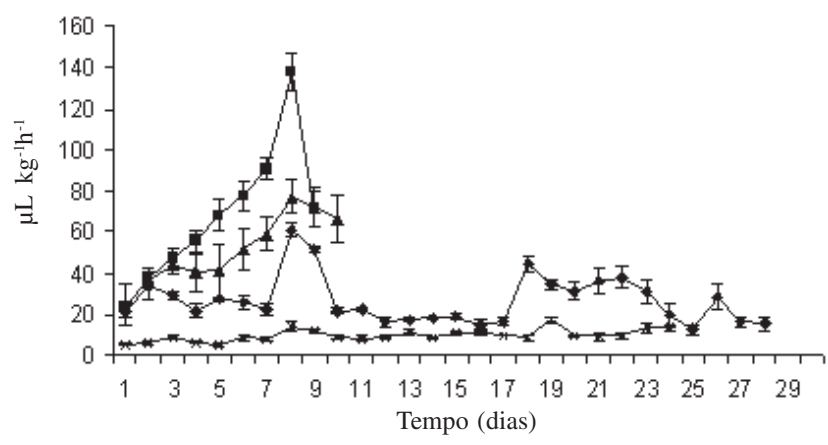

Figura 2. Evolução de $\mathrm{CO}_{2}\left(\mathrm{~mL} \cdot \mathrm{kg}^{-1} \cdot \mathrm{h}^{-1}\right)$ em frutos de buriti (Mauritia vinifera Mart.) armazenados: em conjunto de cinco frutos a $25^{\circ} \mathrm{C}$ em frascos mantidos abertos no ambiente $(\boldsymbol{\square})$, a $25^{\circ} \mathrm{C}$ em frascos com frutos individuais abertos no ambiente $(\boldsymbol{\Delta})$, em conjunto de cinco frutos a $25^{\circ} \mathrm{C}$ mantidos em frascos fechados com passagem de ar $(\diamond)$ e em conjunto de cinco frutos a $8^{\circ} \mathrm{C}$ em frascos mantidos abertos $(\times)$. As barras de intervalo representam o erro padrão da média.
Nos frascos abertos sob umidade mais baixa (65 a 85\%) os picos climatéricos para evolução de $\mathrm{CO}_{2}$ e etileno foram mais evidentes do que sob no tratamento com restrita passagem de ar. Adicionalmente, verificou-se uma correlação positiva entre a produção de $\mathrm{CO}_{2}$ e de etileno para frutos armazenados em conjunto e individualmente dentro de frascos mantidos abertos a $25^{\circ} \mathrm{C}$. À medida que aumentava a evolução do etileno ao longo dos dias, aumentava também a evolução de $\mathrm{CO}_{2}$, contudo, houve um atraso de cerca de dois dias no pico de evolução $\mathrm{CO}_{2}$ com relação ao do etileno. Esta precedência do pico de evolução do etileno tem sido tomada como indicativo de que o etileno seria a causa do pico climatérico de evolução de $\mathrm{CO}_{2}$ nestes produtos. Sabe-se que concentrações elevadas de etileno na atmosfera interna causam aumentos de evolução de $\mathrm{CO}_{2}$. $\mathrm{O}$ aumento da evolução de etileno (Fig. 1) foi de cerca de 20 vezes, resultado comparável com aqueles relatados por Burg \& Burg (1965) no qual a concentração de etileno aumentou cerca de dez vezes em abacate (Persea americana) e ao redor de quinze vezes em banana (Musa sp.) desde o mínimo pré-climatérico até o pico climatérico.

A partir do décimo dia de armazenamento houve o descarte e frutos dos tratamentos em frascos abertos à temperatura ambiente, pois estes se encontravam completamente maduros. Contudo, os frutos dos outros dois tratamentos, frutos em conjunto a $8^{\circ} \mathrm{C}$ e frutos em conjunto em frascos com restrita passagem de ar a $25^{\circ} \mathrm{C}$, ainda estavam com suas características iniciais preservadas e não se encontravam amadurecidos. Após o $10^{\circ}$ dia não houve diferença significativa entre estes dois tratamentos restantes tanto no que diz respeito à evolução de etileno quanto de $\mathrm{CO}_{2}$. No entanto, o amadurecimento procedeu de maneira completa e adequada nos frutos mantidos em frascos com restrita passagem de ar a $25^{\circ} \mathrm{C}$, enquanto que houve a ocorrência de injúrias por frio, a $8{ }^{\circ} \mathrm{C}$, o que impediu o amadurecimento, mesmo quando estes frutos foram retornados para a câmara à temperatura de $25^{\circ} \mathrm{C}$.

Nas medições da composição de $\mathrm{O}_{2}$ e $\mathrm{CO}_{2}$ nos frascos com dois orifícios de $1 \mathrm{~cm}^{2}$ observou-se que as concentrações destes gases no interior dos frascos foram de $20 \%$ e de $0,5 \%$, respectivamente. Estas concentrações de $\mathrm{O}_{2}$ e $\mathrm{CO}_{2}$ e no interior destas câmaras de umidade elevada de acordo com (Luengo \& Calbo 2001) são modificações insuficientes para causar benefícios de atraso de amadurecimento causado por atmosfera modificada. Segundo estes autores são necessárias concentrações de $\mathrm{O}_{2}$ inferiores a $10 \%$ e concentrações de $\mathrm{O}_{2}$ superiores a $1 \%$ para causar substanciais atrasos no amadurecimento de frutos. Segundo Burg \& Burg (1965) uma atmosfera tida como ideal para a preservação de frutos na pós-colheita deve conter entre 5 e $10 \%$ de $\mathrm{CO}_{2}$, sem causar toxidez, e de 1 a $3 \%$ de $\mathrm{O}_{2}$ por ocasionar, nestas quantidades, o efeito de atmosfera modificada que gera benefícios pós-colheita. Desta maneira fica evidenciado que o fato dos frutos do buriti terem o seu amadurecimento atrasado em cerca de 20 dias é devido ao efeito da alta umidade relativa e neste 
sentido não se recuperou na literatura referência de fruto no qual um expressivo aumento da vida útil, mediante o atraso de amadurecimento, tenha sido induzido por um tratamento para reduzir transpiração.

Perda de massa - Para os frutos armazenados a $25^{\circ} \mathrm{C} \mathrm{em}$ frascos com restrita passagem de ar a perda de massa foi mais lenta (Fig. 3), aproximadamente 0,1 grama por dia por fruto, sendo que cada fruto de buriti pesava inicialmente cerca de $70 \mathrm{~g}$. Nos frutos de buriti armazenados a $25^{\circ} \mathrm{C}$ em frascos abertos a perda média de massa foi cerca dez vezes maior, aproximadamente 1 grama por fruto por dia. Armazenados em frascos abertos individualmente os frutos de buriti a $25^{\circ} \mathrm{C}$ apresentaram perda de massa diária ainda maior, de $1,2 \mathrm{~g}$. Para os frutos de buriti armazenados em conjunto a $8^{\circ} \mathrm{C}$ a média diária de perda de massa por fruto foi de $0,8 \mathrm{~g}$ por fruto por dia. A elevada perda de massa dos frutos a $8{ }^{\circ} \mathrm{C}$ deveu-se ao afrouxamento das escamas da casca o que facilitou a perda de água por transpiração. Comparativamente, em um ensaio a $18^{\circ} \mathrm{C}$ Souza et al. (1984) observou uma perda de cerca de $0,5 \mathrm{~g}$ por fruto dia enquanto que a uma temperatura ambiente maior a perda foi de 1,8 g.dia ${ }^{-1}$ por fruto. No estudo de Souza et al. (1984) em câmara a $18{ }^{\circ} \mathrm{C}$ a perda de água foi cerca de cinco vezes maior que no ensaio a $25^{\circ} \mathrm{C}$ com restrita passagem de ar e o registro de tempo para amadurecimento foi de sete dias enquanto que no presente estudo, com menor perda de água, mesmo a uma temperatura maior o amadurecimento foi mais lento e ocorreu em 29 dias.

Os sintomas observados de injúria por resfriamento (chilling) nos frutos armazenados a $8{ }^{\circ} \mathrm{C}$ foram a coloração opaca da polpa, escamas não tão bem encaixadas, porém firmemente aderidas, e perda da capacidade de amadurecimento dos frutos, mesmo quando estes foram retornados para a temperatura ambiente. Descoloração de polpa causada por injúria de resfriamento observada nos frutos de buriti é compatível com a descoloração relatada em outros frutos por Pesis et al. (2002) para o abacate (Persea americana) e por Wang (2002) para o abacaxi (Ananas comosus (L.) Merr) e a banana (Musa sp.).

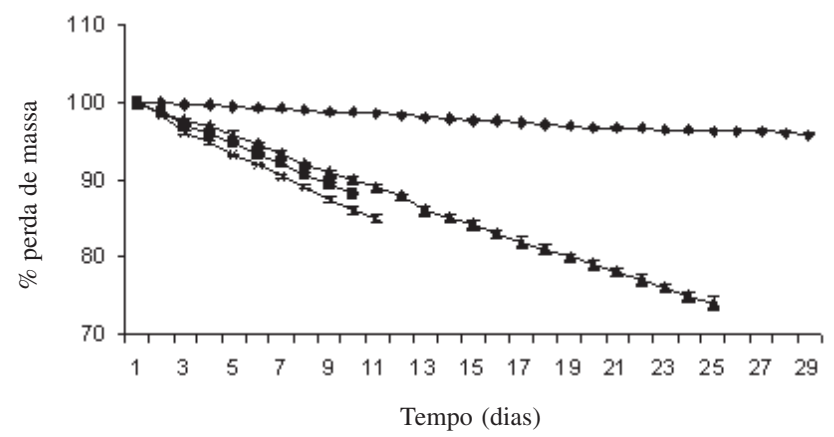

Figura 3. Porcentagem de perda de massa em função do tempo de armazenamento, em frutos de buriti (Mauritia vinifera Mart.) armazenados a: $25^{\circ} \mathrm{C}$ em frascos mantidos abertos no ambiente contendo cinco frutos ( $\left.\mathbf{\square}\right)$, $25^{\circ} \mathrm{C}$ em frascos mantidos abertos no ambiente com frutos individuais $(x)$, $25^{\circ} \mathrm{C}$ em frutos mantidos em frascos com reduzida passagem de ar contendo cinco frutos $(\diamond)$ e a $8{ }^{\circ} \mathrm{C}$ em frascos mantidos abertos contendo cinco frutos $(\boldsymbol{\Delta})$. As barras de intervalo representam o erro padrão da média.
Diferentemente, em melão Hardenburg et al. (1986) relata apenas atraso de amadurecimento, porém sem a ocorrência de escurecimento. $\mathrm{O}$ estabelecimento de aberturas entre as escamas nos frutos do buriti, que propicia aumento de transpiração, causada pela injúria de resfriamento é um sintoma característico não relatado anteriormente na literatura para outros frutos.

Volumes gasosos intercelulares - $\mathrm{O}$ volume gasoso intercelular medido nos frutos do buriti foi na média 1,02\%, a polpa representa $59 \%$ deste volume e a semente $41 \%$. O volume gasoso intercelular encontrado para o fruto do buriti o coloca na faixa de órgãos com baixa quantidade de volumes gasosos intercelulares, como por exemplo, a batata e a cenoura. Como sugere Crisosto (2004) valores assim baixos de volume gasoso intercelular podem ser indicativos de que os frutos de buriti sejam rígidos e mais sensíveis à injúria de impacto, que no caso pode ocasionar descolamento de escamas e adicionalmente, de que estes frutos, com coloração marrom clara, suportam bem o transporte graças à sua boa resistência à compressão.

Atmosfera interna - A concentração interna de $\mathrm{O}_{2} \mathrm{e} \mathrm{CO}_{2}$ na atmosfera interna do fruto de buriti variou diferentemente no tempo para os frutos mantidos em frascos abertos em comparação com os frutos mantidos em frascos com restrita passagem de ar (Fig. 4). A concentração interna de $\mathrm{O}_{2}$ iniciou-se com valores ao redor de $15 \%$ no primeiro dia, em ambos os tratamentos, e a seguir esta concentração aumentou mais rapidamente nos frutos em frascos abertos até atingir quase $20 \%$ no $7^{\circ}$ dia. Por outro lado, nos frutos mantidos em frascos com uma restrita passagem de ar a concentração de $\mathrm{O}_{2}$ na atmosfera interna reduziu-se inicialmente e depois aumentou, porém não atingindo valores de concentração tão elevados quanto o controle em frascos abertos. $\mathrm{O}$ aumento da concentração de $\mathrm{O}_{2}$ no interior do fruto em ambos os tratamentos deveu-se à abertura das escamas, o que facilitou a entrada do $\mathrm{O}_{2}$ por difusão através da casca.

Os mesmos sintomas do fruto explicam os resultados para as concentrações de $\mathrm{CO}_{2}$ na Fig. 4, visto que este gás se movimenta para do fruto, enquanto o $\mathrm{O}_{2}$ é consumido na respiração. Assim, a concentração de $\mathrm{CO}_{2}$ inicialmente ao redor de $6 \%$, em ambos os tratamentos, diminuiu mais rapidamente nos frascos abertos e aproximou-se de $1 \%$ no sétimo dia. Diferentemente, nos frutos mantidos em frascos com restrita passagem de ar houve uma pequena elevação da concentração de $\mathrm{CO}_{2}$ Neste tratamento a concentração de $\mathrm{CO}_{2}$ na atmosfera interna reduziu-se até $2,5 \%$.

Os padrões observados para as variações das concentrações interna de $\mathrm{CO}_{2}$ e de $\mathrm{O}_{2}$ no tempo podem ser interpretadas mediante a noção de resistência difusiva. É interessante observar que enquanto ocorria aumento climatérico de evolução de $\mathrm{CO}_{2}$ (Fig. 2), ao mesmo tempo, ocorria redução da concentração de $\mathrm{CO}_{2}$ na atmosfera interna. Este resultado foi muito diferente daquele observado nos frutos da palmeira gueroba (Syagrus 
oleracea), nos quais a taxa de evolução climatérica de $\mathrm{CO}_{2}$ foi acompanhada de similar padrão climatérico para a concentração de $\mathrm{CO}_{2}$ na atmosfera interna, graças à manutenção resistência difusiva praticamente constante no tempo, para aquele fruto (Santelli et al. 2006). Diferentemente, nos frutos de buriti a resistência difusiva diminuiu no tempo, para se ter uma idéia a resistência de $2,95 \mathrm{~kg} \mathrm{~L}^{-1} \mathrm{~h}^{-1}$ na fase pré-climatérica reduziu-se para $0,69 \mathrm{~kg} \mathrm{~L}^{-1} \mathrm{~h}^{-1}$ no pico climatérico nos frutos em frascos abertos. Interessantemente, para os frutos com ventilação restrita no qual o amadurecimento foi atrasado similar redução na resistência difusiva da casca de frutos não foi observada. Esta redução na resistência difusiva ocorreu principalmente após o pico climatérico. Este padrão temporal particular da concentração da atmosfera interna de $\mathrm{O}_{2}$ e $\mathrm{CO}_{2}$ talvez seja único do fruto do buriti que contém escamas cuja movimentação causou diminuição da resistência à difusão dos gases através da casca.

Os valores de resistência difusiva da casca para frutos relatados na literatura geralmente é estável no armazenamento e variam de 0,5 em frutos de elevada condutividade gasosa como a nectarina (Prunus persica var. nucipersica Dippel) (Calbo e Sommer 1987) até valores ao redor de 7 em certas cultivares maçã (Malus sp.) (Burg \& Burg 1965). No caso do buriti diferentemente de outros frutos a resistência difusiva teve elevada capacidade reguladora e reduziu-se de $2,95 \mathrm{~kg} \mathrm{~L}^{-1} \mathrm{~h}^{-1}$ no fruto pré-climatérico para $0,69 \mathrm{~kg} \mathrm{~L}^{-1} \mathrm{~h}^{-1}$ nos frutos em pleno pico climatérico. Por uma questão de concisão, não se apresentou figura especifica para resistência difusiva que de certa forma seria uma repetição do conteúdo informativo das figuras 2 e 4, visto que a magnitude da resistência difusiva é dada como a razão entre a concentração da atmosfera interna de $\mathrm{CO}_{2}$ (Fig. 4) e taxa respiratória (Fig. 2).

Firmeza - Foi observada uma forte redução da firmeza da polpa dos frutos, mantidos em frascos abertos no ambiente em função do tempo de armazenamento (Fig. 5). A firmeza decresceu paulatinamente até o sétimo dia e entre o sétimo e o oitavo dia, coincidindo com o climatério, houve uma brusca diminuição da firmeza, com o valor sendo reduzido de 0,3 kgf para 0,05 kgf. Os frutos nos primeiros dias após a colheita encontravam-se firmes, com as escamas firmemente aderidas à sua superfície. Na mesma proporção em que a firmeza decrescia as escamas perdiam a aderência à polpa e se tornavam mais facilmente removíveis.

\section{Conclusões}

1) Evidenciou-se que o fruto do buriti apresenta comportamento climatérico com o pico de evolução de $\mathrm{CO}_{2}$ iniciando-se após o pico de evolução de etileno.

2) O fruto do buriti é um fruto sensível à injúria de resfriamento ou "chilling" e em temperaturas inferiores a $8{ }^{\circ} \mathrm{C}$ e os sintomas da injúria são o escurecimento da polpa, a separação das escamas e a perda da capacidade de amadurecimento quando o fruto é retornado para armazenamento a $25^{\circ} \mathrm{C}$.

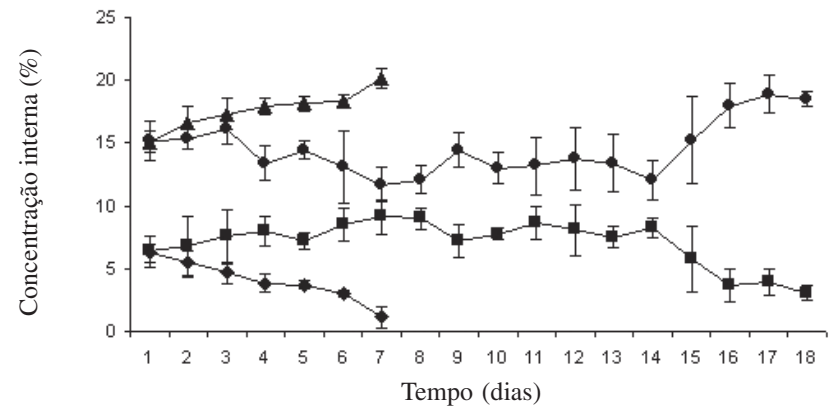

Figura 4. Concentração interna de $\mathrm{O}_{2}$ (porcentagem) em frutos de buriti (Mauritia vinifera) durante o processo de amadurecimento a $25^{\circ} \mathrm{C}$ para frutos armazenados em conjunto em frascos que foram mantidos em frascos com reduzida passagem de ar $(\boldsymbol{\Delta})$ e para frutos armazenados em frascos mantidos plenamente abertos $(\bullet)$. Concentração interna de $\mathrm{CO}_{2}$ (porcentagem) em frutos de buriti (Mauritia vinifera Mart.) durante o processo de amadurecimento a $25^{\circ} \mathrm{C}$ para frutos armazenados em conjunto em frascos que foram mantidos em frascos com reduzida passagem de ar (ם) e armazenados em frascos mantidos plenamente abertos $(\bullet)$. As barras representam o erro padrão das médias.

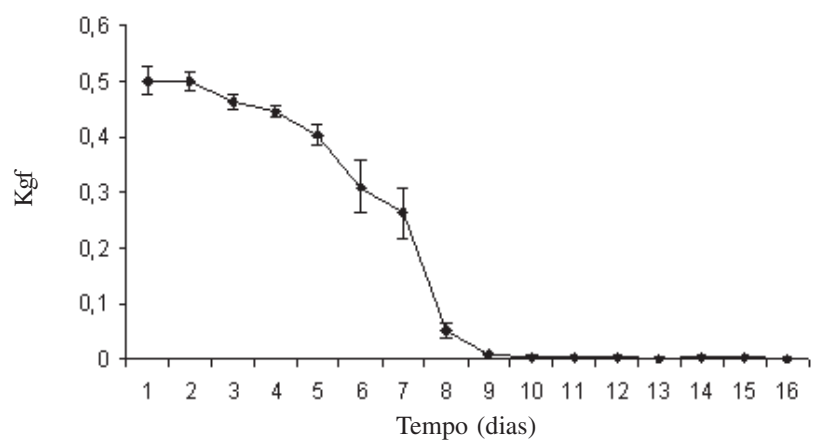

Figura 5. Mudança na firmeza dependente da composição bioquímica e amadurecimento na polpa dos frutos de buriti (Mauritia vinifera Mart.), medida com penetrômetro acoplado a ponteira cilíndrica de $3 \mathrm{~mm}$ diâm., ao longo do processo de amadurecimento. As barras de intervalo representam o erro padrão da média.

3) $\mathrm{O}$ armazenamento dos frutos de buriti em conjunto causou efeito sinérgico de aumento da evolução de etileno e de aceleração do amadurecimento em comparação com os frutos armazenados individualmente.

4) Os frutos de buriti apresentam reduzido volume gasoso intercelular.

5) A firmeza da polpa dos frutos do buriti, medida com penetrômetro, diminui durante o amadurecimento e tornase quase nula após o pico climatérico.

6) A vida útil de pós-colheita dos frutos do buriti pode ser triplicada graças ao atraso no amadurecimento causado por aumento da umidade e redução na taxa de transpiração. Este efeito de estresse hídrico é mediado por um atraso nos picos de evolução do etileno e de $\mathrm{CO}_{2}$ e não é causado por efeito de atmosfera modificada.

7) As curvas de concentração de $\mathrm{CO}_{2}$ e de $\mathrm{O}_{2}$ na atmosfera interna do buriti diferem das de outros frutos climatéricos estudados, por evidenciarem uma grande redução da resistência difusiva da casca, causada pela formação de aberturas entre as escamas, o que ocorre no começo do pico climatérico e que é acelerado quando o produto é sujeito a elevadas taxas de transpiração. 


\section{Referências bibliográficas}

Amarante, C.V.T. \& Megguer, C.A. 2008. Qualidade pós-colheita de frutos de butiá em função do estádio de maturação na colheita e do manejo da temperatura. Ciência Rural 38: 46-53.

Biale, J.B.; Young, R.E. \& Olmstead, A.J. 1954. Fruit respiration and ethylene production. Plant Physiology 29: 168-174.

Burg, S.P. \& Thimann, K.V. 1960. Studies on ethylene production of apple tissue. Plant Physiology 35: 24-35.

Burg, S.P. \& Burg, E.A. 1965. Ethylene action and the ripening of fruits. Science 148: 1190-1196.

Calbo, A.G. \& Moretti, C.L. 2005. Penetrômetro a gás para a avaliação da firmeza de frutos. Embrapa-Hortaliças URL: http://www.cnph.embrapa.br/laborato/pos_colheita/ penetrometro.htm (Acesso em: 20/03/2008).

Calbo, A.G. \& Sommer, N.F. 1987. Intercellular volume and resistance to mass air flow of fruits and vegetables. Journal of the American Society for Horticultural Science 112: 131-134.

Calbo, M.E.R.; Lima, J.N. \& Calbo, A.G. 1990. Fisiologia pós- colheita de frutos de cagaita. Revista Brasileira de Fisiologia Vegetal 2: $15-18$.

Correa, M. Pio. 1931. Dicionário de Plantas Úteis do Brasil. Ministério da Agricultura. Rio de Janeiro, Imprensa Nacional.

Crisosto, C.H. 2004. Handling preconditioned tree fruit at the retail distribution centers. Central Valley Postharvest Newsletter 13: $1-3$.

Hardenburg, R.E.; Watada, A.E. \& Wang, C.Y. 1986. The commercial storage of Fruits, Vegetables, and Florist and Nursery Stocks Agriculture Handbook $\mathbf{N}^{\circ}$ 66. Davis, U.S. Department of Agriculture.
Henderson, A.; Galeano, G. \& Bernal, R. 1995. Field Guide to the Palms of the Americas. New Jersey, Princeton University Press.

Jensen, C.R.; Luxmore, R.J.; Van Grundy, S.D. \& Stolzy, L.H. 1969. Root air space measure by a pycnometer method. Agronomic Journal 61: 474-475.

Lorenzi, H.; Souza, H.M.; Madeiros-Costa, J.T.; Cerqueira, L.S.C. \& Ferreira, E. 2004. Palmeiras Brasileiras e Exóticas Cultivadas. Nova Odessa, Plantarum.

Luengo, R.F.A. \& Calbo, A.G. 2001. Armazenamento de hortaliças. Brasília, Embrapa Hortaliças.

Pesis, E.; Ackerman, M.; Ben-Arie, R.; Feygenberg, O.; Feng, X.; Apelbaum, A.; Goren, R. \& Prusky, D. 2002. Ethylene involvement in chilling injury symptoms of avocado during cold storage. Postharvest Biology and Technology 24: 171-181.

Santelli, P.; Calbo, M.E.R. \& Calbo, A.G. 2006 Fisiologia pós-colheita de frutos da palmeira Syagrus oleracea (Mart.) Becc. (Arecaceae). Acta Botanica Brasilica 20: 523-528.

Souza, M.C.P.; Maia, G.A.; Guedes, Z.B.L.; Oriá, H.F. \& Holanda, L.F.F. 1984. Amadurecimento natural e artificial do buriti. Pesquisa Agropecuária Brasileira 19: 891-896.

Wang, C.Y. 2002. Chilling and Freezing Injury In: Gross, K.C. Agriculture Handbook 66(HB-66). Beltsville, USDA, ARS.

Zonta, E.P. \& Machado, A.A. 1995. Sistemas de análises estatísticas (SANEST) para microcomputadores. Pp.17-18. In: Simpósio de Estatística Aplicada à Experimentação. Campinas, Fundação Cargil. 